\title{
Ask the Experts: How Can New Students Defend Behavior Analysis from Misunderstandings?
}

\author{
Amel Becirevic \\ Published online: 9 September 2014 \\ (C) Association for Behavior Analysis International 2014
}

\begin{abstract}
The success of behavior analysis as a field depends on the successes of its students, researchers, practitioners, and advocates. A new generation of graduate students will ultimately speak on the behalf of the field. In order to further promote the field, students must not only learn about what behavior analysis is, but also about what behavior analysis is not. We must prepare ourselves to adequately defend behavior analysis from those who disseminate misperceptions and misunderstandings. As such, an electronic survey designed to glean some information on how behavior analysts would respond to various inaccuracies or misunderstandings of behavior analysis was distributed through behavior-analytic listservs and social media websites. Findings show that the majority of respondents indicate that any graduate student ought to correct the misunderstandings about the field. What do seasoned behavior analysts have to say about the majority opinion about the responsibilities of graduate students and what recommendations do they have for new graduate students who come across misunderstandings about behavior analysis?
\end{abstract}

Keywords Misunderstanding $\cdot$ Behavior analysis .

Misconception · Dissemination

Behavior analysis is both "alive and well" (Baum 2000, p. 263) despite what some students of mainstream psychology might think. As a new graduate student in behavior analysis, I find that my colleagues and I are troubled when our field is misunderstood, and even more so when it is misunderstood by prominent scholars from other fields. Of course, people who misunderstand the field are not entirely to blame. As Skinner

A. Becirevic $(\triangle)$

Department of Applied Behavioral Science, University of Kansas, 4085 Dole Human Development Center, 1000 Sunnyside Avenue, Lawrence, KS 66045-7555, USA

e-mail: amel@ku.edu
(1977) stated, "I long ago adopted the basic rule in animal research that the organism is always right. It does what it is induced to do by its genetic endowment or the prevailing conditions" (p. 1007). People, too, have idiosyncratic ontogenic behavioral histories (Skinner 1981). Thus, critics of behavior analysis are not to blame for misunderstanding behavior analysis. To understand why others perpetuate misunderstandings of behavior analysis, we would need to critically examine the prevailing conditions that give rise to those misunderstandings, which is outside the scope of the present paper. For our part, we behavior analysts bear the burden of adequately understanding our own field before speaking for the field. This puts me and my colleagues - a new generation of students in behavior analysis - in a predicament: How can one champion the field if one does not fully understand the field?

Like any other science behavior analysis has evolved. Its philosophical precursor, behaviorism, can be attributed to John Watson's (1878-1958) epistemic advancement from science infused with mentalism (Fredericks 2006). For example, Watson (1913) criticized the psychology of consciousness studied through introspective methods and advanced the psychology of behavior studied with objective methods of experimentation, and advocated for the goals of prediction and control of behavior. Unfortunately, many of the antibehavioral views can be attributed to mischaracterized representations of Watson's own work (Lattal \& Rutherford 2013; Todd \& Morris 1992). At best, even Skinner's publications of works such as Walden Two in 1948 and Beyond Freedom and Dignity in 1971 spurred controversies; at worst, these controversies sparked criticism and misunderstanding.

Just as Watson wrote over a century ago, "I do not wish unduly to criticize psychology" (1913, p. 163), neither do I wish for behavior analysis to be criticized. As Brave New World Revisited reminds us:

Everything that is done within a society is done by individuals. These individuals are, of course, profoundly 
Table 1 Hypothetical scenarios with misunderstandings of behavior analysis

\begin{tabular}{|c|c|}
\hline Question 1 & $\begin{array}{l}\text { Suppose a graduate student overhears someone } \\
\text { in public comment that behavior analytic services } \\
\text { for autism are akin to simple dog training. Should } \\
\text { the student interject and attempt to correct this } \\
\text { misconception? }\end{array}$ \\
\hline Question 2 & $\begin{array}{l}\text { Suppose a graduate student enrolled in a cognitive } \\
\text { psychology course is told by the instructor that } \\
\text { behavior analysis is "black box psychology" and } \\
\text { that "behaviorism is dead." Should the student } \\
\text { attempt to correct this misconception? }\end{array}$ \\
\hline Question 3 & $\begin{array}{l}\text { Suppose a graduate student consulting in a clinical } \\
\text { agency overhears a licensed psychologist comment } \\
\text { that behavior analytic services rely on bribes and } \\
\text { treat clients inhumanely. Should the student interject } \\
\text { and attempt to correct this misconception? }\end{array}$ \\
\hline Question 4 & $\begin{array}{l}\text { Suppose a graduate student attending a psychology } \\
\text { conference hears a doctoral-level presenter state } \\
\text { that reliance on visual inspection of single-subject } \\
\text { design is inferior to inferential statistics. Should the } \\
\text { student approach the presenter privately following } \\
\text { her talk and attempt to correct this misconception? }\end{array}$ \\
\hline Question 5 & $\begin{array}{l}\text { Suppose a graduate student reads an online news } \\
\text { story that suggests that behavior analysis is "black } \\
\text { box psychology" and relies on bribes and treats } \\
\text { clients inhumanely. Should the student contact the } \\
\text { journalist to attempt to correct this misconception? }\end{array}$ \\
\hline
\end{tabular}

influenced by the local culture, the taboos and moralities, the information and misinformation handed down from the past and preserved in a body of spoken traditions or written literature; but whatever each individual takes from society...will be used by him in his own unique way. (Huxley 1958, p. 105)

Although not a behavior analyst, Huxley's quote resonates with Skinner's statements about the importance of prevailing conditions. As other behavior analysts have suggested (Poling 2010; Schlinger 2010), I too urge students of behavior analysis to broaden their perspectives by reading and publishing beyond the boundaries of our field and to challenge the tensions produced by the psychology of the Zeitgeist!

Behavior analysts have written extensively about the most common misunderstandings and strategies for correcting them (e.g., Kestner \& Flora, 1995; Todd \& Morris, 1992). To build on these discussions, I attempted to investigate the popular opinion of behavior analysts when it comes to misunderstandings of the field. I distributed an electronic survey through behavior analytic listservs (Teaching Behavior Analysis [TBA-listserv]) and social media accounts (personal tweets and Facebook groups [Association for Behavior Analysis International, The Analysis of Verbal Behavior, Behavior Analysis in Practice, Disseminating Behavior Analysis, Students of Applied Behavior Analysis] wall posts). The rationale for recruiting via the internet was to survey the
Table 2 The eight responses provided in each scenario

\begin{tabular}{|c|c|}
\hline Response 1 & $\begin{array}{l}\text { Yes, any graduate student in this context should } \\
\text { attempt to correct this misconception. }\end{array}$ \\
\hline Response 2 & $\begin{array}{l}\text { Yes, but only once they've completed at least } \\
\text { one course in behavior analysis }\end{array}$ \\
\hline Response 3 & $\begin{array}{l}\text { Yes, but only once they've had a presentation/poster/ } \\
\text { paper accepted for dissemination by a behavior } \\
\text { analytic organization. }\end{array}$ \\
\hline Response 4 & $\begin{array}{l}\text { Yes, but only once they've completed their } \\
\text { Master's degree. }\end{array}$ \\
\hline Response 5 & $\begin{array}{l}\text { Yes, but only once they've completed their Master's } \\
\text { degree and had a presentation/poster/paper accepted } \\
\text { for dissemination by a behavior analytic organization. }\end{array}$ \\
\hline Response 6 & $\begin{array}{l}\text { Yes, but only once they've passed their oral } \\
\text { comprehensive examinations related to behavior } \\
\text { analysis and become doctoral candidates. }\end{array}$ \\
\hline Response 7 & $\begin{array}{l}\text { Yes, but only once they've passed their oral } \\
\text { comprehensive examinations related to behavior } \\
\text { analysis and become doctoral candidates and had a } \\
\text { presentation/poster/paper accepted for dissemination } \\
\text { by a behavior analytic organization. }\end{array}$ \\
\hline Response 8 & $\begin{array}{l}\text { No, graduate students should never attempt to correct } \\
\text { this misconception in this context. }\end{array}$ \\
\hline
\end{tabular}

perspectives of the widest possible range of behavior analysts. The purpose of the survey was to provide information about how, in the opinion of respondents, graduate students should respond when they hear other people voice misunderstandings of behavior analysis.

Respondents were 167 individuals from behavior analytic listservs and social media outlets $(M$ age $=36.6$ years, $S D$ age $=11.9$ years; $57 \%$ female). The respondents selected from a list the positions that most resembled their current ones. The reported positions were clinicians (44\%), researchers and professors $(27 \%)$, students $(16 \%)$, and others (13\%). With respect to reported time spent working, 29, 28, 23, 15, and $5 \%$ reported working $6-10,2-5,11-20,>20$, and about 1 year(s), respectively. The survey described five situations in which someone misunderstood, and in that sense misrepresented, behavior analysis and was overheard by a graduate student in behavior analysis (Table 1). Respondents were asked to select from a list of eight responses how the student should

Table 3 Percentage of responses for each scenario

\begin{tabular}{llllllllr}
\hline Questions & \multicolumn{7}{l}{ Responses (\%) } \\
\cline { 2 - 8 } & 1 & 2 & 3 & 4 & 5 & 6 & 7 & 8 \\
\hline 1 & 60 & 14 & 2 & 3 & 0 & 1 & 0 & 20 \\
2 & 67 & 17 & 1 & 3 & 1 & 2 & 0 & 9 \\
3 & 67 & 17 & 1 & 6 & 0 & 2 & 0 & 6 \\
4 & 46 & 15 & 5 & 9 & 2 & 8 & 2 & 14 \\
5 & 59 & 14 & 1 & 7 & 2 & 3 & 5 & 9 \\
\hline
\end{tabular}

Refer to Tables 1 and 2 for complete list of questions and responses 
respond. The options ranged from "Yes, any graduate student in this context should attempt to correct this misconception" to "No, graduate students should never attempt to correct this misconception in this context (Table 2)."

Table 3 shows the percentage of respondents who selected each response option for each of the five situations. In every case, the most selected response, with $46-67 \%$ of respondents selecting it across scenarios, was "Yes, any graduate student in this context should attempt to correct this misconception" (response 1). Overall, the second-most-often selected response, chosen by $14-17 \%$ of respondents across scenarios, was "Yes, but only once they've completed at least one course in behavior analysis" (response 2). Response 8, "No graduate students should ever attempt to correct this misconception in this context," was selected slightly less often than response 2 , with $6-20 \%$ of respondents selecting response 8 across scenarios.

Based on my initial assumption that graduate students should have a good understanding of behavior analysis before speaking for the field, the findings of the survey were surprising. The majority of respondents indicated that any graduate student should serve as an ambassador for behavior analysis, even a first-year student, and attempt to correct misunderstandings. A limitation of this survey, however, was that it provided limited response options. A few emails from respondents indicated a desire for conditional responses, such as "if the student did well in a course" or "if the student had direct behavior-analytic experience." These comments seem to suggest that there are limitations on the conditions under which students should serve as ambassadors for the field and that the actual opinions of respondents are not as clear cut as the reported results suggest.

For example, one respondent indicated that he or she wished for response options that were individualized to the scenario being presented. Another stressed that competency in a particular area, a dimension not directly reflected in the response options provided, is more important that degrees held or current position in determining how a person should respond to the scenarios provided. For example, perhaps an individual who specializes in the area of feeding disorders should not defend behavior analysis against misrepresentations pertaining to substance abuse. Giving experts in behavior analysis an unconstrained opportunity to address the issue of how graduate students should respond when they hear their field misrepresented will extend the findings reported here, provide practical guidance for graduate students, and undoubtedly prove interesting. I invite them to address the following questions:

\section{Questions for the Experts}

1. Given that the majority of respondents indicated that any graduate student should attempt to correct misconceptions, what possible steps can graduate students take to defend the discipline from misunderstandings by people outside of the field?

2. Speaking on behalf of the behavior-analytic community obviously occurs during any point of professional development. At what stage of professional development should behavior analysts reach out to the broader scientific community to disseminate behavior analysis?

\section{References}

Baum, W. M. (2000). Alive and kicking: a review of Handbook of Behaviorism, edited by William O'Donoghue and Richard Kitchener. Journal of Applied Behavior Analysis, 33, 263-270. doi:10.1901/jaba.2000.33-263.

Fredericks, D. W. (2006). The evolution of scientific psychology. In B. D. Midgley \& E. K. Morris (Eds.), Modern perspectives on J. R. Kantor and interbehavioral psychology (pp. 39-62). Reno: Context Press.

Huxley, A. (1958). Brave new world revisited. New York: HarperCollins.

Kestner, J., \& Flora, S. R. (1995). Representation of behavioral methodology in experimental psychology textbooks. The Behavior Analyst, $18,385-390$.

Lattal, K. A., \& Rutherford, A. (2013). John B. Watson's behaviorist manifesto at 100. Mexican Journal of Behavior Analysis, 39, 1-9.

Poling, A. (2010). Looking to the future: will behavior analysis survive and prosper? The Behavior Analyst, 33, 7-17.

Schlinger, H. D. (2010). Perspectives on the future of behavior analysis. The Behavior Analyst, 33, 1-5. doi:10.1037/0003-066x.32.12.1006.

Skinner, B. F. (1977). Herrnstein and the evolution of behaviorism. American Psychologist, 32, 1006-1012.

Skinner, B. F. (1981). Selection by consequences. Science, 213, 501-504. doi:10.1126/science.7244649.

Todd, J. T., \& Morris, E. K. (1992). Case histories in the great power of steady misinterpretation. American Psychologist, 47, 1441-1453. doi:10.1037/0003-066X.47.11.1441.

Watson, J. B. (1913). Psychology as the behaviorist views it. Psychological Review, 20, 158-177. doi:10.1037/h0074428. 